\title{
Estrategias cognitivas de aprendizaje que emplean niños estudiantes principiantes de italiano
}

\author{
Cognitive learning strategies used by children taking a beginner Italian course \\ Claudia A. Fuerte-León ${ }^{a}$, Ma. De Lourdes Rico-Cruz ${ }^{b}$, Delphine Pluvinet ${ }^{c}$
}

\begin{abstract}
:
This article presents the partial results of a research study focused on the analysis and reflection of the cognitive strategies of repetition, elaboration and organization used by children aged 8 to 11 while they are studying Italian at a beginning level.

The study consisted of five sessions of an Italian course where didactic units were carefully designed with different learning activities with the purpose of yielding useful information for the selection, observation and analysis of the strategies employed in kids learning this foreign language.

The results of this research are expected to have an important impact in the field of language teaching to children; so that once the teachers consider the type of cognitive effort that learners these ages make, they can design more meaningful language courses and activities for them.
\end{abstract}

\section{Keywords:}

Learning strategy, cognitive strategy, repetition, elaboration, organization

\section{Resumen:}

Este artículo presenta los resultados iniciales de un trabajo de investigación que se enfocó en el análisis y reflexión de las estrategias cognitivas de repetición, elaboración y organización que emplean los niños de 8 a 11 años mientras estudiaban italiano nivel principiante.

El estudio constó de 5 sesiones de italiano donde se llevaron a cabo unidades didácticas con diferentes actividades que arrojaron información útil para la selección, observación y análisis de las estrategias empleadas en el aprendizaje de esta lengua.

Se espera que los resultados de esta investigación tengan un impacto trascendental en el campo de la enseñanza de lenguas a niños; de tal manera que los profesores al conocer el tipo de esfuerzo cognitivo que realizan los estudiantes de estas edades, puedan diseñar cursos y actividades más significativas para ellos.

\section{Palabras Clave:}

Estrategia de aprendizaje, estrategia cognitiva, repetición, elaboración, organización

\section{INTRODUCCIÓN}

Actualmente, se vive en un mundo totalmente globalizado donde todas las personas nos conectamos con todos los demás y un idioma constituye una gran herramienta al momento de comunicarnos. Hoy en día, conocer otras lenguas se ha convertido en un requisito indispensable para acercarnos a las diversas áreas del conocimiento y al desarrollo humano ya que el aprendizaje de un idioma no solo acrecienta la posibilidad de conseguir un mejor trabajo, sino también enriquece la vida social y cultural. El aprendizaje de otros idiomas permite enriquecer la vida, experimentar nuevas ideas, ejercitar la mente, beneficiarse de la diversidad cultural mundial, obtener becas para estudios de posgrado, trabajar en una empresa

a Correspondence Author, Universidad Autónoma de Querétaro, Facultad de Lenguas y Letras, https://orcid.org/0000-0001-6479-467X, Email: claudia.fuerte@gmail.com

b Universidad Autónoma de Querétaro, Facultad de Lenguas y Letras, https://orcid.org/0000-0001-9836-3886, Email: ricoc@uaq.mx

Universidad Autónoma de Querétaro, Facultad de Lenguas y Letras, https://orcid.org/0000-0001-7083-8691, Email: 
transnacional, además de poder expresarse con otros, aumentando así las relaciones sociales.

Algunos autores establecen que es recomendable aprender una segunda lengua desde la infancia. Se piensa que los niños que aprenden una lengua extranjera a temprana edad son capaces de desarrollar sus competencias comunicativas más efectivamente, pues su cerebro está en proceso de desarrollo y asimila el conocimiento de una manera natural. Medina et al. (2013), afirman que los niños aprenden de manera intuitiva y sugieren que el aprendizaje de una lengua extranjera provee al niño un conocimiento sólido y sienta sus bases para nuevos aprendizajes a través del desarrollo de estrategias de aprendizaje que le permitirán en el futuro, una mayor flexibilidad cognitiva y la comprensión de conceptos nuevos.

Las mismas autoras (2013) confirman que un salón de clase podría ser usado como un contexto ideal para el desarrollo de aprendizaje de una lengua extranjera dado que con apoyo del profesor, se pueden hacer y rehacer actividades variadas hasta lograr un aprendizaje productivo. Para ello es recomendable utilizar actividades cortas y variadas para mantener el interés y motivación de los niños.

En la actualidad, el aprendizaje de una lengua extranjera es una disciplina que se ha fomentado de manera global en niños, adolescentes y adultos. Mucho se ha investigado sobre los procesos de adquisición de lenguas en adultos, adolescentes y niños, especialmente en el estudio del inglés. Sin embargo, aun hace falta recorrer un camino largo para conocer los procesos de adquisición y aprendizaje de otras lenguas, tales como el francés o el italiano y su aplicación práctica en la enseñanza de las mismas.

En este sentido, en la búsqueda del indagar un poco más sobre los procesos de aprendizaje en los niños, este trabajo de investigación se diseñó con el propósito principal de observar, analizar y reflexionar sobre las estrategias cognitivas, que usa un niño al aprender una lengua extranjera como el italiano. De igual manera, con el análisis de resultados y las observaciones pertinentes, se pretende conocer cuáles emplean los niños más frecuentemente en sus clases. Considerando lo anterior, surgen las siguientes preguntas de Investigación en este proyecto:
1. ¿Cuáles estrategias cognitivas de aprendizaje usan los niños de ocho a once años en una clase de italiano nivel principiantes?

2. ¿Cuáles son las características y las diferencias entre las estrategias empleadas por los niños según sus edades y sus rasgos propios?

\section{LITERATURA Y MARCO CONCEPTUAL}

\subsection{Estrategias de Aprendizaje}

Grenfell y Macaro (2007), definen las estrategias como una forma de actividad que es empleada para dar respuesta a un problema y que éstas establecen una conexión entre el contexto social y psicológico de la persona. De alguna u otra manera, las personas estamos inmersos en la resolución de dificultades que se presentan en nuestra vida cotidiana y se generan alternativas de acción distintas para abordar las problemáticas y así, se forma en nosotros el pensamiento estratégico.

En el campo del aprendizaje de las lenguas, los aprendientes se enfrentan constantemente a problemáticas que deben ser resueltas. En ese sentido, Rebeca Oxford (1990) afirma que un aprendiente de lenguas desarrolla estrategias de aprendizaje que le permiten avanzar en su competencia comunicativa con mayor autoconfianza. Según Weinstein y Mayer (1986) las estrategias de aprendizaje son conductas y pensamientos que el aprendiz utiliza durante el proceso de aprendizaje con la intención de influir en su proceso de comunicación ante las dificultades que se le presentan.

Es importante señalar que los autores especifican que las estrategias son consideradas procedimientos que se aplican de un modo intencional y liberado a una tarea y no pueden reducirse a rutinas automatizadas. Es decir, las estrategias tienen un carácter intencional e implican un plan de acción frente a la técnica que es mecánica y rutinaria (Oxford:1990).

Según O’Malley y Chamot (1990) existen 3 tipos de Estrategias:

$>$ Estrategia Metacognitiva- Ésta involucra el reflexionar sobre el proceso de aprendizaje a través de la cual, es 
estudiante planea para aprender, monitorea su comprensión y lleva a cabo una autoevaluación.

$>$ Estrategia Cognitiva- Comprende tareas de aprendizajes individuales que presentan manipulación de materiales y actividades propias de aprendizaje.

$>$ Estrategia Socioafectiva- Este tipo de estrategia considera la influencia de los procesos sociales y afectivos en el aprendizaje.

Por lo tanto, se define la Estrategia como un plan general para alcanzar un logro o meta y las estrategias de aprendizaje son el conjunto de actividades que posibilitan la comunicación, el aprendizaje y el autocontrol de este por parte del aprendiz.

\subsection{Estrategias Cognitivas y su clasificación}

Chadwick (1988), describe las estrategias cognitivas como procesos de dominio general para el control del funcionamiento de las actividades mentales. También especifica que los procesos cognoscitivos incluyen algunas actividades como la percepción, la atención, el procesamiento, el almacenamiento, la recuperación de la información, la creatividad y las relaciones afectivas.

En el aprendizaje de lenguas, estos procesos representan destrezas que el alumno adquiere durante un período de varios años para manejar su propio proceso de atender, aprender, pensar y resolver problemas. A través de la adquisición y el refinamiento de estas estrategias el alumno llega a ser un aprendiz y pensador independiente. Weinstein y Mayer (citado en Valle, 2000) describen las estrategias cognitivas de aprendizaje como conductas y pensamientos que activa el alumno con el fin de realizar eficazmente el proceso de codificación del material de aprendizaje. Dichas estrategias tienen como objetivo principal integrar el nuevo conocimiento con el previo.

A continuación, se presenta la clasificación de estrategias de los autores antes mencionados:

1. Microestrategias-estrategias que favorecen los procesos de adquisición y almacenamiento organizado de la nueva información aprendida en el sistema cognitivo de la memoria. Estas son: repetición y elaboración.
2. Macroestategias-estrategias que contribuyen en los procesos de evocación y utilización de la información aprendida con un nivel de conciencia por parte del aprendiz, del propio proceso de aprendizaje. Estas son: organización y regulación.

Esta investigación se enfocará en tres estrategias específicamente de las mencionadas: repetición, elaboración y organización. Por lo cual se hace una breve descripción de cada una de ellas.

\section{a) Repetición}

Consiste en nombrar, decir, escuchar o copiar de forma repetida el contenido a aprender. Esta estrategia debe complementarse con la elaboración asegurando el paso de la información de la memoria de trabajo y corto plazo a largo plazo.

\section{b) Elaboración}

Consiste en llevar a cabo un proceso significativo de la información. En esta etapa el alumno se involucra en el aprendizaje y relaciona los conocimientos previos con los nuevos.

\section{c) Organización}

Consiste en buscar métodos con los cuales sea más sencillo acceder y comprender la información. Supone la categorización, ordenación y estructuración de los contenidos.

\section{METODOLOGÍA DEL ESTUDIO}

El trabajo de investigación que se presenta en este artículo se desarrolló como un estudio de caso, con un enfoque cualitativo y de corte etnográfico y descriptivo. Se llevó a cabo una observación minuciosa de las actividades estratégicas de los niños al realizar diversas actividades durante 5 sesiones de clases de italiano a nivel principiante. En esta sección se presenta la información más relevante.

\subsection{Los participantes y el estudio}

Inicialmente, se contó con la participación de ocho participantes que oscilaban entre los seis y once años de edad. Debido a la complejidad de la información, la diferencia en edades y la poca constancia de los niños más pequeños, se tomó la decisión de sólo enfocar el estudio en cuatro de ellos; los 
mayores. Así, se consideraron solo cuatro participantes; uno de ocho años, otro de nueve, uno de diez y el último de once años. Todos ellos eran estudiantes de escuela primaria pública. La mayoría de ellos ya había estado en contacto con el aprendizaje del inglés. Para efectos de la presentación de los resultados en este artículo, el participante 1 será el niño de ocho años, el participante 2 el de nueve, y así sucesivamente; de tal manera que los participantes 3 y 4 son los mayores.

Estos participantes asistieron a 5 sesiones sabatinas de una hora, en las cuáles se llevaron a cabo diferentes actividades para desarrollar habilidades de la lengua italiana, como son: la comprensión auditiva, producción oral y producción escrita. Se trabajó con videos de canciones para sensibilizar al alumno y posteriormente se propusieron actividades de comprensión y repetición.

Todas las sesiones se registraron en formato video y audio para su análisis. Las grabaciones de audio fueron hechas para revisar y transcribir los diálogos e interacciones de todos los participantes. Todo lo observado se registró en un diario de campo así como una guía de observación, donde se analizaron las diferentes etapas de la clase, los procesos y las actuaciones de los participantes.

\subsection{Instrumentos}

Para recolectar la información, se utilizaron tres instrumentos:

1) Una encuesta a los padres de los niños participantes para conocer algunos datos personales e información específica respecto a las actividades que realiza el niño en la escuela y en su casa. Esta encuesta fue piloteada y modificada y su aplicación permitió tener un panorama sobre el perfil de los estudiantes.

2) Se diseñaron 5 unidades didácticas donde se especificaron datos generales del curso, los objetivos, las competencias y habilidades a trabajar, la duración de las actividades, la etapa de la clase, la metodología empleada, las modalidades de trabajo y los materiales o herramientas usadas. También contiene la bibliografía consultada y los sitios de internet empleados para los videos y materiales. En la elaboración de las sesiones, se revisaron y pilotearon varias actividades que permitieran generar la información que se buscaba y de igual forma, se seleccionaron los materiales para que fueran atractivos para los niños y además útiles para que se diera el aprendizaje en el aula.

3) Para analizar los datos obtenidos en formato y video se empleó un diario de campo donde se describieron las actividades y procesos de todas las sesiones. Además, incluye una guía de observaciones donde se registraron todas las reacciones y actividades que llevaron a cabo los niños. Las sesiones fueron grabadas en audio y video, y posteriormente fueron recolectados $y$ vaciados en computadora. Ambas formas de recolección de datos permitieron contemplar las actuaciones de todos los participantes, así como reflexionar sobre a sus reacciones, actuaciones y participaciones en clase a través del formato de observación.

\subsection{Unidades Didácticas}

Las cinco secuencias didácticas que se diseñaron especifican datos generales del curso, los objetivos, las competencias y habilidades a trabajar, la metodología empleada, las modalidades de trabajo y los materiales o herramientas a usar. La tabla 1, señala los temas trabajados en cada una de las cinco sesiones con las actividades que se realizaron.

\begin{tabular}{|c|c|c|c|}
\hline Sesión & Tema & Actividad & Descripción de la actividad \\
\hline 1 & $\begin{array}{l}\text { La } \\
\text { presentazione- } \\
\text { Nome, età, } \\
\text { studi ecc. } \\
\text { (presentaciones: } \\
\text { nombre, } \\
\text { estudio, etc) }\end{array}$ & $\begin{array}{c}\text { Actividad } \\
\text { "A" } \\
\text { Minidiálogo }\end{array}$ & $\begin{array}{l}\text { Se hizo una breve presentación } \\
\text { proporcionando información } \\
\text { personal. En parejas se hizo la } \\
\text { práctica utilizando la información } \\
\text { vista. }\end{array}$ \\
\hline 2 & $\begin{array}{l}\text { L'alfabeto } \\
\text { italiano (el } \\
\text { alfabeto } \\
\text { italiano) }\end{array}$ & $\begin{array}{l}\text { Actividad } \\
\text { "B" } \\
\text { El alfabeto }\end{array}$ & $\begin{array}{l}\text { Se presentaron las letras del } \\
\text { alfabeto con una imagen para } \\
\text { reconocerlas. Después se solicitó al } \\
\text { niño que recordara algunas de las } \\
\text { imágenes vistas. }\end{array}$ \\
\hline 3 & $\begin{array}{l}\text { I giorni della } \\
\text { settimana-La } \\
\text { nascita di un } \\
\text { pulcino (los } \\
\text { días de la } \\
\text { semana, el } \\
\text { nacimiento) }\end{array}$ & $\begin{array}{l}\text { Actividad } \\
\text { "C" } \\
\text { Secuencia } \\
\text { de los días } \\
\text { de la } \\
\text { semana }\end{array}$ & $\begin{array}{l}\text { Se presentaron los días de la } \\
\text { semana y se comentó cuál era el } \\
\text { favorito. Después se realizó un } \\
\text { ejercicio de secuencia donde } \\
\text { debían colocar la palabra del día de } \\
\text { la semana que correspondiera a la } \\
\text { secuencia "ieri-oggi-domani" }\end{array}$ \\
\hline 4 & $\begin{array}{l}\text { I sostantivi- } \\
\text { Persone, } \\
\text { animali ed } \\
\text { oggetti. } \\
\text { (los sustantivos: } \\
\text { personas, } \\
\text { animales y } \\
\text { objetos) }\end{array}$ & $\begin{array}{l}\text { Actividad } \\
\text { "D" } \\
\text { Categoriza- } \\
\text { ción de } \\
\text { sustantivos }\end{array}$ & $\begin{array}{l}\text { Se presentaron de forma mezclada } \\
\text { algunas imágenes de personas, } \\
\text { cosas y animales. Después se pidió } \\
\text { al estudiante que identificara y } \\
\text { clasificara las imágenes vistas en } \\
\text { tres categorías distintas: "persona- } \\
\text { animale-oggetto". }\end{array}$ \\
\hline
\end{tabular}




\begin{tabular}{|l|l|c|l|}
\hline 5 & $\begin{array}{l}\text { Il racconto-"I } \\
\text { musicanti di } \\
\text { Brema" (la } \\
\text { historia - "los } \\
\text { músicos de } \\
\text { Bremen") }\end{array}$ & $\begin{array}{c}\text { Actividad } \\
\text { "E" } \\
\text { Dibujar la } \\
\text { historia del } \\
\text { cuento }\end{array}$ & $\begin{array}{l}\text { Se observó un vídeo de un cuento } \\
\text { en italiano "I musicanti di Brema" } \\
\text { y se cuestionó a los niños sobre qué } \\
\text { habían entendido. Por último, se les } \\
\text { pidió que dibujaran la historia en 6 } \\
\text { viñetas. }\end{array}$ \\
& & \\
\hline
\end{tabular}

Tabla 1. Descripción de las actividades de las sesiones

\section{RESULTADOS Y SU ANÁLISIS}

Durante las actividades mencionadas en la tabla 1, se pudo observar lo siguiente:

ACTIVIDAD A. En esta actividad comunicativa que tuvo como objetivo hacer una breve presentación de sí mismos, los cuatro participantes hicieron una actividad significativa porque conocieron información propia y conocieron a los demás niños, lo cual los motivó para que pudieran emplear lo visto en clase.

ACTIVIDAD B. El objetivo de la actividad fue la memorización de las letras del alfabeto. Los participantes 1 y 2 (P1 y P2), sólo repitieron las letras del alfabeto. Los participantes 3 y 4 (P3 y P4) compararon el alfabeto italiano con el alfabeto del inglés. También mencionaron sobre algunas letras que no existen en italiano, como el caso de la J y de la K, lo cual indica que estos niños (los más grandes) tienen un nivel de pensamiento más complejo, es decir, podían hacer una comparación entre la estructura del español o del inglés, con el italiano.

ACTIVIDAD C. Consistió en hacer la secuencia ordenada de los días de la semana. En esta actividad debían relacionar el día de la semana de acuerdo a las categorías propuestas: ayer-hoymañana. En esta actividad los participantes 3 y 4 pudieron ordenar correctamente los días de la semana, mientras que los participantes más jóvenes 1 y 2 se equivocaron en varias ocasiones y no pudieron concluir el ejercicio.

ACTIVIDAD D. Consistió en relacionar imágenes y acomodarlas en las categorías: personas, animales y cosas. El participante 2 realizó el ejercicio con errores que después corrigió al observar las respuestas de los demás. Los participantes 1 y 2 hicieron el ejercicio de manera más lenta y con cuidado. Mientras que los participantes 3 y 4 terminaron la actividad rápidamente.
ACTIVIDAD E. En esta sesión, se presentó un vídeo de un cuento en italiano que los cuatro participantes observaron con atención. Después la maestra preguntó cuál era el tema de cuento; sólo los participantes mayores (P3 y P4) pudieron explicarlo en pocas palabras, resumiéndolo y en la lengua materna, la L1. Mientras que el niño más pequeño, el participante 1 sólo comentó que se trataba de amigos y el participante 2 mencionó tres nombres de los animales protagonistas de la historia. En la segunda fase de la actividad se solicitó que dibujarán la historia en seis viñetas; los P3 y P4 pudieron realizar los seis dibujos solicitados mientras que los niños más pequeños P1 y P2 solo hicieron tres; es decir, no completaron la actividad.

Si consideramos los resultados de las tres estrategias cognitivas por participante, los resultados arrojan lo siguiente:

a) Estrategias de repetición.

En general, se puede observar que todos los participantes repiten la información que se les da de una manera u otra. Esta estrategia emerge de manera natural en el aprendizaje de una lengua. En el caso de la última sesión, no sucedió así, quizás por el tipo de actividad donde se requería sólo de atender el video y a las imágenes.

Cabe señalar que esta estrategia se centra únicamente en la repetición de palabras o frases en el momento de recibir la información, lo cual es distinto a recordar y traer al momento una información ya aprendida. Aunque la repetición de palabras de manera oral y escrita se observa en todos los niños, la complejidad del proceso no es igual para todos. Es decir, se puede observar mayor intento de imitación por parte de los participantes más jóvenes, los cuales cometen errores en su imitación (P1- ver tabla 2) mientras que los participantes mayores presentan mayor transferencia de otras lenguas en sus repeticiones, como sucede en el caso del participante 3 (ver tabla 4). En este proceso de repetición es importante mencionar que se observa también claramente que los niños identifican una imagen o un sonido con las palabras que están repitiendo; es decir, se generan representaciones mentales del objeto con su nombre o una frase con una situación comunicativa. 


\begin{tabular}{|c|c|c|c|}
\hline ACTIVIDAD & REPETICIÓN & ELABORACIÓN & ORGANIZACIÓN \\
\hline a. Minidiálogo & $\begin{array}{l}\text { Copió y repitió } \\
\text { la información. }\end{array}$ & $\begin{array}{l}\text { No pudo relacionar } \\
\text { la información } \\
\text { nueva con la } \\
\text { previa, }\end{array}$ & $\begin{array}{l}\text { Pudo hacer el } \\
\text { diálogo con ayuda } \\
\text { del P2 }\end{array}$ \\
\hline b. Alfabeto & $\begin{array}{l}\text { Nombró las } \\
\text { letras del } \\
\text { alfabeto, solo se } \\
\text { equivocó en la } \\
\text { pronunciación } \\
\text { de la C y G. }\end{array}$ & $\begin{array}{l}\text { Relacionó las } \\
\text { letras del alfabeto } \\
\text { y su pronunciación } \\
\text { con el inglés. }\end{array}$ & $\begin{array}{l}\text { Pudo comprender el } \\
\text { alfabeto } \\
\text { comparándolo con el } \\
\text { alfabeto en inglés. }\end{array}$ \\
\hline $\begin{array}{l}\text { c. Secuencia } \\
\text { días de la } \\
\text { semana }\end{array}$ & $\begin{array}{l}\text { Repitió en voz } \\
\text { alta los días de } \\
\text { la semana } \\
\text { imitando a la } \\
\text { maestra. }\end{array}$ & $\begin{array}{l}\text { Copió los días de } \\
\text { la semana en el } \\
\text { cuaderno. }\end{array}$ & $\begin{array}{l}\text { En el ejercicio de } \\
\text { secuencia de los días } \\
\text { de la semana no } \\
\text { pudo ordenar de } \\
\text { acuerdo a la } \\
\text { secuencia solicitada. }\end{array}$ \\
\hline $\begin{array}{l}\text { d. } \\
\text { Categorización }\end{array}$ & $\begin{array}{l}\text { Pudo identificar } \\
\text { y repetir el } \\
\text { vocabulario de } \\
\text { las imágenes de } \\
\text { las personas, } \\
\text { objetos y } \\
\text { animales. }\end{array}$ & $\begin{array}{l}\text { Pudo relacionar } \\
\text { sólo algunas } \\
\text { imágenes con su } \\
\text { palabra en italiano. }\end{array}$ & $\begin{array}{l}\text { De manera lenta } \\
\text { pudo colocar todas } \\
\text { las palabras en la } \\
\text { categoría } \\
\text { correspondiente de } \\
\text { personas, objetos y } \\
\text { animales, }\end{array}$ \\
\hline $\begin{array}{l}\text { e. Dibujar la } \\
\text { historia del } \\
\text { cuento }\end{array}$ & $\begin{array}{l}\text { Solo observó el } \\
\text { vídeo del } \\
\text { cuento, sin } \\
\text { repetir nada. }\end{array}$ & $\begin{array}{l}\text { Pudo mencionar } \\
\text { algunos personajes } \\
\text { de la historia }\end{array}$ & $\begin{array}{l}\text { Sólo pudo dibujar } 3 \\
\text { de las seis viñetas } \\
\text { solicitadas. }\end{array}$ \\
\hline
\end{tabular}

Tabla 2.- Observaciones participante 1 (8 años)

a) Estrategia de elaboración.

Esta estrategia trata de llevar a la acción cualquier actividad que sea de traer al momento la información previa. En este proceso se puede observar que los participantes pueden hacer una relación directa entre las diferencias que existen entre la lengua materna, el inglés (que tendría el rol de una segunda lengua) con la lengua nueva (en este caso, el italiano) - ver tablas 2, 3 y 4.

\begin{tabular}{|l|l|l|l|}
\hline ACTIVIDAD & REPETICIÓN & ELABORACIÓN & ORGANIZACIÓN \\
\hline a. Minidiálogo & $\begin{array}{l}\text { Copió y repitió } \\
\text { la información. } \\
\text { Pero necesitó } \\
\text { apoyo para } \\
\text { elaborar el } \\
\text { diálogo. }\end{array}$ & $\begin{array}{l}\text { Pudo relacionar la } \\
\text { información nueva } \\
\text { con la previa, pero } \\
\text { necesitó apoyo de } \\
\text { la maestra. }\end{array}$ & $\begin{array}{l}\text { Pudo hacer el } \\
\text { diálogo con ayuda } \\
\text { del P1. }\end{array}$ \\
\hline b. Alfabeto & $\begin{array}{l}\text { Nombró las } \\
\text { letras del } \\
\text { alfabeto. Repitió } \\
\text { varias veces, } \\
\text { aunque por } \\
\text { sugerencia del } \\
\text { docente }\end{array}$ & $\begin{array}{l}\text { Copió el alfabeto en } \\
\text { el cuaderno. }\end{array}$ & $\begin{array}{l}\text { Pudo comprender el } \\
\text { alfabeto } \\
\text { relacionándolo con } \\
\text { sus notas. }\end{array}$ \\
\hline $\begin{array}{l}\text { c. Secuencia } \\
\text { días de la } \\
\text { semana }\end{array}$ & $\begin{array}{l}\text { Repitió en voz } \\
\text { alta los días de } \\
\text { la semana. }\end{array}$ & $\begin{array}{l}\text { Copió el } \\
\text { vocabulario de los } \\
\text { días de la semana } \\
\text { en el cuaderno. }\end{array}$ & $\begin{array}{l}\text { En el ejercicio de } \\
\text { secuencia de los días } \\
\text { de la semana pudo } \\
\text { ordenarlos de } \\
\text { manera lenta. }\end{array}$ \\
\hline
\end{tabular}

\begin{tabular}{|l|l|l|l|}
\hline $\begin{array}{l}\text { d. } \\
\text { Categorización }\end{array}$ & $\begin{array}{l}\text { Pudo identificar } \\
\text { y repetir el } \\
\text { vocabulario de } \\
\text { las imágenes de } \\
\text { las personas, } \\
\text { objetos y } \\
\text { animales. }\end{array}$ & $\begin{array}{l}\text { Solicitó a la } \\
\text { maestra la escritura } \\
\text { del vocabulario en } \\
\text { italiano, lo copio y } \\
\text { después pudo } \\
\text { entenderlo. }\end{array}$ & $\begin{array}{l}\text { Colocó todas las } \\
\text { palabras en la } \\
\text { categoría } \\
\text { correspondiente de } \\
\text { personas, objetos y } \\
\text { animales, }\end{array}$ \\
\hline $\begin{array}{l}\text { e. Dibujar la } \\
\text { historia del } \\
\text { cuento }\end{array}$ & $\begin{array}{l}\text { Observó el vídeo } \\
\text { del cuento. }\end{array}$ & $\begin{array}{l}\text { Pudo comentar cuál } \\
\text { fue el tema del } \\
\text { cuento, mencionó } \\
\text { algunos nombres de } \\
\text { animales, los } \\
\text { recordó. }\end{array}$ & $\begin{array}{l}\text { Dibujó 4 de las seis } \\
\text { viñetas solicitadas. }\end{array}$ \\
\hline
\end{tabular}

Tabla 3.- Observaciones participante 2 (9 años)

Se puede observar también que es común tomar notas en la clase, sin que la maestra les pida hacerlo. En este sentido, es importante notar que esta estrategia es aprendida y transferida de las clases que llevan en su escuela. Este tipo de actividades de aprendizaje tienen un efecto positivo en el aprendizaje de una segunda o tercera lengua. La complejidad de esta estrategia de acuerdo a las distintas edades también es evidente en este trabajo. Es decir, se puede ver que entre más chicos los niños, más ayuda necesitan tanto del profesor como de sus compañeros para completar la tarea (ver tablas 2 y 3 ), mientras que los niños mayores ya pueden hacer relaciones más complejas al recordar información; tales como contrastar una lengua con otra (ver tabla 4). Además se observa que el profesor es un referente importante para los estudiantes más grandes (ver tabla 4 y 5 actividad 1 -sesión 1).

En la última actividad del cuento, la complejidad del uso de estrategias de elaboración se observa claramente. Por ejemplo, en los participantes más pequeños ( 1 y 2 ), se puede sugerir que sólo contestan a preguntas específicas de comprensión tales como mencionar los personajes del cuento y el nombre del cuento, quizás el tema en general (ver tablas 2 y 3); mientras que los participantes más grandes pueden dar detalles del cuento e incluso explicar la moraleja o enseñanza del cuento; aunque sea usando la lengua materna (el español).

\section{b) Estrategia de organización}

Por último, esta estrategia trata de elaborar actividades mentales más complejas de clasificación, orden, secuencia que se reflejan en la producción de una actividad como podría ser un escrito. En este apartado se reflejará el análisis de esta estrategia. 
Como se puede observar, los participantes más pequeños (P1 y P2) tuvieron dificultades para completar las actividades, fueron un poco más lentos y requirieron de más ayuda por parte de sus compañeros (ver tablas 2 y 3 ).

También tuvieron más errores en cuanto a la categorización de conceptos abstractos, como el tiempo y los días de la semana. Por otro lado, para los participantes 3 y 4 , se observó que las actividades no representaban problemas para ellos, es decir, completaron las tareas de manera rápida y eficaz (ver tablas 4 y 5).

\begin{tabular}{|l|l|l|l|}
\hline \multicolumn{1}{|c|}{ ACTIVIDAD } & REPETICIÓN & ELABORACIÓN & ORGANIZACIÓN \\
\hline a. Minidiálogo & $\begin{array}{l}\text { Repitió la } \\
\text { información con } \\
\text { algunos errores de } \\
\text { pronunciación } \\
\text { mezcló algunos } \\
\text { sonidos con el } \\
\text { inglés. }\end{array}$ & $\begin{array}{l}\text { Pudo relacionar la } \\
\text { información nueva } \\
\text { con la previa, } \\
\text { recordando el } \\
\text { ejemplo de la } \\
\text { maestra. }\end{array}$ & $\begin{array}{l}\text { Pudo hacer el diálogo } \\
\text { con ayuda del P4 y al } \\
\text { mismo tiempo apoyó a } \\
\text { P1 y P2 }\end{array}$ \\
\hline $\begin{array}{l}\text { b. Alfabeto } \\
\text { Repitió las letras } \\
\text { del alfabeto. }\end{array}$ & $\begin{array}{l}\text { Copió el alfabeto } \\
\text { en el cuaderno y } \\
\text { preguntó porque no } \\
\text { existían las letras J } \\
\text { K, como en el } \\
\text { español. }\end{array}$ & $\begin{array}{l}\text { Pudo comprender el } \\
\text { alfabeto } \\
\text { relacionándolo con sus } \\
\text { notas y con el español. }\end{array}$ \\
\hline $\begin{array}{l}\text { c. Secuencia } \\
\text { días de la } \\
\text { semana }\end{array}$ & $\begin{array}{l}\text { Repitió en voz alta } \\
\text { los días de la } \\
\text { semana. }\end{array}$ & $\begin{array}{l}\text { Copió el } \\
\text { vocabulario de los } \\
\text { días de la semana } \\
\text { en el cuaderno. }\end{array}$ & $\begin{array}{l}\text { En el ejercicio de } \\
\text { secuencia de los días } \\
\text { de la semana pudo } \\
\text { ordenarlos } \\
\text { rápidamente. }\end{array}$ \\
\hline $\begin{array}{l}\text { raviaria del } \\
\text { cuento }\end{array}$ & $\begin{array}{l}\text { Observó, } \\
\text { atentamente, el } \\
\text { vídeo del cuento. }\end{array}$ & $\begin{array}{l}\text { Mencionó de qué } \\
\text { trataba la historia } \\
\text { en la lengua } \\
\text { materna (L1) }\end{array}$ & $\begin{array}{l}\text { Dibujó las 6 viñetas } \\
\text { solicitadas } \\
\text { rápidamente. Incluyó } \\
\text { la moraleja. }\end{array}$ \\
\hline $\begin{array}{l}\text { Repitió las palabras } \\
\text { en italiano. }\end{array}$ & $\begin{array}{l}\text { Solicitó a la } \\
\text { maestra la escritura } \\
\text { del vocabulario en } \\
\text { italiano, lo copió y } \\
\text { después pudo } \\
\text { entenderlo. }\end{array}$ & $\begin{array}{l}\text { Entendió rápidamente } \\
\text { el ejercicio y colocó } \\
\text { todas las palabras en la } \\
\text { categoría } \\
\text { correspondiente. }\end{array}$ \\
\hline
\end{tabular}

Tabla 4.- Observaciones participante 3 (10 años)

\begin{tabular}{|l|l|l|l|}
\hline ACTIVIDAD & REPETICIÓN & ELABORACIÓN & ORGANIZACIÓN \\
\hline a. Minidiálogo & $\begin{array}{l}\text { Repitió la } \\
\text { información } \\
\text { correctamente }\end{array}$ & $\begin{array}{l}\text { Pudo relacionar la } \\
\text { información nueva } \\
\text { con la previa, } \\
\text { recordando el } \\
\text { ejemplo de la } \\
\text { maestra. }\end{array}$ & $\begin{array}{l}\text { Pudo hacer el diálogo } \\
\text { y apoyó al P 1 y P2 }\end{array}$ \\
\hline b. Alfabeto & $\begin{array}{l}\text { Nombró las letras } \\
\text { del alfabeto } \\
\text { correctamente }\end{array}$ & $\begin{array}{l}\text { Copió, de manera } \\
\text { ordenada el alfabeto } \\
\text { en el cuaderno. Y } \\
\text { observó que no era } \\
\text { igual que el alfabeto } \\
\text { en español. }\end{array}$ & $\begin{array}{l}\text { Pudo comprender el } \\
\text { alfabeto } \\
\text { relacionándolo con } \\
\text { sus notas. }\end{array}$ \\
\hline
\end{tabular}

\begin{tabular}{|l|l|l|l|}
\hline $\begin{array}{l}\text { c. Secuencia } \\
\text { días de la } \\
\text { semana }\end{array}$ & $\begin{array}{l}\text { Repitió en voz alta } \\
\text { los días de la } \\
\text { semana. }\end{array}$ & $\begin{array}{l}\text { Copió el vocabulario } \\
\text { de los días de la } \\
\text { semana en el } \\
\text { cuaderno. }\end{array}$ & $\begin{array}{l}\text { En el ejercicio de } \\
\text { secuencia de los días } \\
\text { de la semana pudo } \\
\text { ordenarlos } \\
\text { rápidamente y de } \\
\text { manera correcta. }\end{array}$ \\
\hline $\begin{array}{l}\text { d. } \\
\text { Categorización }\end{array}$ & $\begin{array}{l}\text { Repitió el } \\
\text { vocabulario de las } \\
\text { imágenes } \\
\text { solicitando apoyo } \\
\text { de la maestra. }\end{array}$ & $\begin{array}{l}\text { Solicitó a la maestra } \\
\text { la escritura del } \\
\text { vocabulario en } \\
\text { italiano, lo copio y } \\
\text { después lo entendió }\end{array}$ & $\begin{array}{l}\text { Colocó todas las } \\
\text { palabras en la } \\
\text { categoría } \\
\text { correspondiente de } \\
\text { personas, objetos y } \\
\text { animales rápidamente. }\end{array}$ \\
\hline $\begin{array}{l}\text { e. Dibujar la } \\
\text { historia del } \\
\text { cuento }\end{array}$ & $\begin{array}{l}\text { Observó el vídeo } \\
\text { del cuento. }\end{array}$ & $\begin{array}{l}\text { Mencionó algunos } \\
\text { nombres de animales } \\
\text { yudo comentar el } \\
\text { tema del cuento. } \\
\text { Incluso mencionó la } \\
\text { moraleja en L1. }\end{array}$ & $\begin{array}{l}\text { Dibujó las 6 viñetas } \\
\text { solicitadas de una } \\
\text { manera detallada y } \\
\text { rápida. }\end{array}$ \\
\hline
\end{tabular}

\section{Tabla 5.- Observaciones participante 4 (11 años)}

\section{CONCLUSIONES}

Para concluir esta investigación y haciendo referencia a la primera pregunta sobre cuáles estrategias emplearon los niños se observó que todos los participantes emplearon la estrategia de repetición, la cual se presenta de manera natural en los niños. Es importante señalar que los estudiantes más jóvenes (de ocho y nueve años) realizan más trabajo de imitación e identificación mientras que los estudiantes más grandes (de diez y once años) tienen una repetición con menos errores.

En cuanto a la estrategia de elaboración los participantes toman notas para ayudar a su proceso de memorización y traer la información al momento, lo cual, se presume, es una estrategia aprendida y transferida de sus clases de la escuela. También se puede observar en general que los participantes trabajan apoyándose unos con otros.

En la última etapa de organización se observó que los P1 y P2 confundieron las secuencias de los días de la semana, lo cual no les permitió contestar correctamente el ejercicio. Los P3 y P4 organizaron su información mediante listados de palabras. Al final, todos los participantes pudieron categorizar las palabras de las imágenes. En actividades más complejas como de comprensión y ordenar secuencias o eventos, sólo los niños más grandes pudieron completarlo. Lo cual sugiere ser una actividad con mayor dificultad. 
Respecto a la segunda pregunta de esta investigación sobre si las características influyen en el modo de aprendizaje, efectivamente se confirma que se percibió que cada uno de los participantes mantuvo su propio estilo de aprendizaje, sin dejar a un lado las características propias de su personalidad. Complementariamente, se pudo observar que los niños mayores pudieron realizar las actividades de manera más simple, mientras que los niños menores lo hicieron lentamente, en ocasiones con errores e incluso, hubo tareas que no lo pudieron completar.

Teniendo en consideración los aspectos observados en la presente investigación se considera pertinente para futuros estudios, el observar si con otros participantes de las mismas edades se dan los mismos resultados en cada una de las actividades propuestas. De igual manera, será importante investigar de qué forma influye cada etapa evolutiva de los niños en las estrategias cognitivas. Así mismo, sería relevante conocer de qué manera influye el tener ya un conocimiento previo de una L2 en el aprendizaje de una tercera lengua y si se emplean las mismas estrategias de aprendizaje de L2 en el aprendizaje de una L3.

\section{REFERENCIAS}

CEA, Alvarez Ana María. (2017). Revisión del concepto de Estrategia en el proceso de adquisición y aprendizaje de segundas lenguas. Lenguas a la luz de las nuevas Investigaciones. Universidad Do Minho, Portugal. DOI:http://dx.doi.org/10.21814/diacritica.34

Chadwick, Clifton B. (1988). Estrategias Cognoscitivas y afectivas de aprendizaje. Revista Latinoamericana de Psicología Vol. 20, núm. 002. Fundación Universitaria Konrad Lorenz. Bogotá, Colombia. http://www.redalyc.org/pdf/805/80520202.pdf

Dorado, C. (1997): Aprender a Aprender: Estrategias y Técnicas. Universidad Autónoma de Barcelona. http://www.xtec.es/cdorado1/esp/est-tec.htm

Gargallo, Bernardo, Suárez-Rodríguez, Jesús M. y Pérez-Pérez, Cruz (2009). El cuestionario CEVEAPEU. Un instrumento para la evaluación de las estrategias de aprendizaje de los estudiantes universitarios. RELIEVE, $\begin{array}{lllll}v . & 15, & \text { n. } & \text { p. } & 1-31 \text {. }\end{array}$ http://www.uv.es/RELIEVE/v15n2/RELIEVEv15n2_5.htm

Grenfell, M. y Macaro, E. (2007). Climes and Critiques. En Cohen, A. D. y Macaro, E. Language Learning Strategies (pp 9-28).

Oxford: Oxford University Press. Reino Unido.

O’Malley, J. M. y Chamot A. U. (1990). Learning Strategies in Second Language Acquisition. New York. Cambridge University Press. Reino Unido

Oxford, R. L. (1990). Language Learning Strategies: What Every Teacher Should Know. Boston, Mass: Heinle \& Heinle Publishers.
Peña Pellicer, Ma. Teresa (2013). Relación entre las estrategias de aprendizaje y el rendimiento escolar en alumnos de sexto curso de educación primaria. UNIR Universidad Internacional De La Rioja. Valencia, España.

Rubin, J. (1987). Learner Strategies in Language Learning. New Jersey: Prentice Hall.

Vivás, Nidia Angélica (2010). Estrategias de Aprendizaje. Revista Gondola (ISSN 2145-4981) Vol. 5 No. 1.

Valle, Antonio et al (2000). Las estrategias de aprendizaje: características básicas y su relevancia en el contexto escolar. Revista de Pscicodidáctica, No. 6, pp 53-68. Universidad del País Vasco, España. 